\title{
Commentary
}

\section{Sustainable Product Indexing: Navigating the Challenge of Ecolabeling}

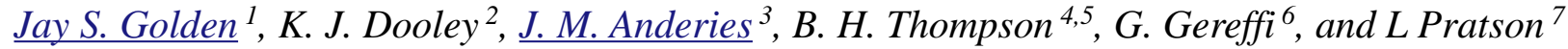

\begin{abstract}
There is growing scientific evidence that improving the sustainability of consumer products can lead to significant gains in global sustainability. Historically, environmental policy has been managed by bureaucracies and institutions in a mechanistic manner; this had led to many early successes. However, we believe that if policy concerning product sustainability is also managed in this way, negative unintended consequences are likely to occur. Thus, we propose a social-ecological systems approach to policy making concerning product sustainability that will lead to more rapid and meaningful progress toward improving the environmental and social impacts of consumer products.
\end{abstract}

Key Words: consumer products, ecolabeling, sustainable indexing, sustainability

\section{INTRODUCTION}

There is growing evidence that improving consumer-product sustainability will play a critical role in achieving global sustainability goals (Kates et al. 2001). Up to $42 \%$ of all U.S. greenhouse gas (GHG) emissions in $\mathrm{CO}_{2}$ equivalents are associated with materials used for consumer products (U.S. Environmental Protection Agency 2009). Likewise, numerous studies have identified the damages that can arise with our increased demand for agriculturally based consumer products, including pesticide pollution, water depletion, and deforestation (Tillman 1999). Many new electronics products use more power than the ones they are replacing (Horwitz et al. 2005), and the global outsourcing of manufacturing has led to concerns of opportunism on the part of firms against workers in developing countries (Gereffi and Mayer 2004).

These concerns have led to the development of "ecolabels," which are demarcations on a consumer product that certify that the product meets a standard set of criteria with respect to an environmental or social impact. For example, the Marine Stewardship Council and Forest Stewardship Council seals warrant that purchased products were harvested from sustainable fisheries and forests, respectively. Almost all ecolabels focus on a single issue and, because they tend to emerge from coalition-based movements, they have proliferated in number. For example, ConsumerReports Greener Choices identifies 150 consumer product ecolabels. Whereas $95 \%$ of surveyed U.S. consumers indicated that they would buy green (Deloitte and the Grocery Manufacturers Association 2009), the multiplicity of ecolabels has yielded "eco-babble" to the detriment of well-developed and validated labels (see for example, The Economist 1991).

Although not referred to as such at the time, ecolabeling dates back to at least the 1920s with the promulgation of the Official United States Standards for Grades of Carcass Beef. More explicit ecolabeling efforts by the U.S. government date back to the 1975 Energy Policy and Conservation Act (EPCA) that required fuel economy labeling information and standards for city and highway driving (U.S. Environmental Protection Agency 2008). In 1992, the U.S. Environmental Protection Agency (EPA) launched ENERGY STAR, a voluntary program to label computer-related products with information on their energy-use characteristics. ENERGY STAR currently accounts for 60 consumer product categories and, in 2007, prevented the release of 78 million metric tons $\left(\mathrm{MMTCE}^{2}\right.$ ) of greenhouse gases (U.S. Environmental Protection Agency 2008). Both of these programs

\footnotetext{
${ }^{1}$ Nicholas School of the Environment and Nicholas Institute, Duke University Durham, North Carolina., ${ }^{2}$ Supply Chain Management, W. P. Carey School of Business, Arizona State University, ${ }^{3}$ School of Human Evolution and Social Change, Arizona State University, ${ }^{4}$ Woods Institute for the Environment, ${ }^{5}$ Stanford Law School, Stanford University, ${ }^{6}$ Center on Globalization, Governance and Competitiveness, Duke University, ${ }^{7}$ Energy and Environment Program, Nicholas School of the Environment, Duke University
} 
have generally been acknowledged to be successful. This can be attributed in large part to the fact that each label covers a homogenous set of products with easily measurable metrics, has a system in place to validate measurement claims, and has a formal institution to oversee the management of the program. Governments across the globe are now considering ecolabel legislation. In the United States, the Waxman-Markey America Clean Energy and Security Act (HR 2998) would require the EPA to determine the feasibility of establishing a national program for measuring, reporting, publicly disclosing, and labeling products or materials sold in the U.S. for their carbon content. California Assembly Bill 19, known as the Carbon Labeling Act, would require the assessment, verification, and standardized labeling of the carbon footprint of consumer products sold in California. The U.S. Federal Trade Commission has also shown a recent willingness to address false environmental claims on product labels. There are market forces at work as well. Retailers and manufacturers are creating their own labeling systems for consumers (Sammer and Wustenhagen 2006) and industrial buyers (Darnall et al. 2008) who are seeking green products.

\section{ECOLABELING AND UNINTENDED CONSEQUENCES}

In light of this flurry of activity around ecolabels, it is wise to step back and look at the effectiveness of existing ecolabeling programs and to consider how best to move forward from a policy perspective. Traditional environmental regulation can provide valuable lessons. The institutions that guide environmental and public health policy in the U.S. are organized around an "expert" model, in which experts oversee single issues with particular emphasis on managing risk (Allenby and Fink 2005). Programs like the Clean Water Act and Clean Air Act have been developed around simple impact areas using prescriptive limits. Although this approach has been successful because of its focusing of scientific expertise, it is also susceptible to negative unintended consequences (Michener et al. 2001). By singling out a particular component of the system, the approach risks ignoring other interactions that may occur between that part of the system and other relevant outcomes (Steinzor 1998).
Consider the case of corn-based ethanol, whose growth was driven by energy policy. Although subsidized as a gasoline replacement since 1978, ethanol use took off following its inclusion under the renewable fuels standard (RFS) of the 2005 Energy Policy Act. Supported by subsidies along with a tariff and federal production mandate, capacity rose from 7.2 BGPY in 2008 to a current level of 13.4 BGPY, which would consume $39 \%$ of this year's predicted U.S. corn crop (Keeney 2009). There are several negative unintended consequences associated with this policy. The first is increased corn futures prices, which almost doubled in the fall of 2008 relative to 2005 (Tenenbaum 2008) and appears to have affected the prices of foods that use corn as a feedstock (Keeney 2009). Next, ethanol production requires intensive use of water, a critical resource for food production. Furthermore, more land, also critical to food production, is being used for growing corn, threatening native biodiversity (Keeney 2009). Finally, overfertilization of the corn crop may end up leading to more nitrate being carried to the U.S. Gulf of Mexico by surface and ground waters, inhibiting alleviation of the hypoxic zone off the mouth of the Mississippi River (Donner and Kucharik 2008). These deleterious impacts to humans and the environment have raised questions concerning the true benefits of ethanol, which contains less energy than gasoline, yields a low net energy gain in its conversion from corn, and still requires fossil fuels to produce (Hill et al 2006).

The example of "shade coffee" (Mas and Dietsch 2004) demonstrates what can happen when certification programs don't consider holistic effects. Although coffee plants naturally grow under the shade of trees, many coffee growers have developed plants that can grow in full sun, increasing production efficiency, but decreasing biodiversity. Shade-coffee certification programs reward growers whose farms provide higher quality habitat for biodiversity. Unfortunately, shadegrown certification allows for land use ranging from native forest to something resembling a monoculture plantation that is little different from sun coffee in terms of its biodiversity value (Rappole et al. 2003, Mas and Dietsch 2004). Few consumers are actually aware of such distinctions beneath the "shade coffee" label. Furthermore, Rappole et al. (2003) report that the premium price paid for shade coffee has led to large amounts of native forest being replaced with shade coffee plantations and an overall loss of biodiversity. 
Finally, shade-coffee labeling has unintended social consequences as well. The high prices paid for shade coffee have induced local growers to shift from other staple crops, like beans, to coffee, weakening the overall economic resilience of the community (Bacon 2005).

Ecolabeling policy can learn from these examples. A focus on a single impact area, like greenhouse gases, may create unexpected shifts in the behavior of the resource users that render the policy ineffectual at best and damaging at worst (Folke et al. 2002, Holling and Meffe 1996). Likewise, natural resource systems may undergo rapid shifts from one form of organization to another as a result of human intervention aimed at addressing shortterm objectives (Scheffer et al. 2001). Finally, economic interventions may induce Jevons' Paradox (Jevons 1906) or the Rebound Effect (Greene et al. 1999), in which the gains from improved product sustainability are offset by increased levels of consumption.

\section{POLICY RECOMMENDATIONS: CHARTING A WAY FORWARD}

The potential impact of providing information about product characteristics not naturally generated by the market on improving human well-being and the environment is clear. The ENERGY STAR and fuel-economy labeling programs mentioned above are examples of labeling success stories. There are others, such as health-warning labels on cigarettes that contributed to significant declines in smoking in the U.S. However, these cases have common features that contribute to their success: they cover a homogenous set of products, typically with a single, easily measurable impact. In each case, there was a system in place to validate measurement claims and a formal institution to oversee the management of the program. These factors significantly reduce the impact of unintended consequences associated with these programs. As we have argued, ecolabeling programs that attempt to capture information regarding the environmental impact or sustainability characteristics of a product do not share either of these characteristics.

Given the complexities associated with humanenvironment interactions, we propose two measures that should guide the development of ecolabeling policy: (1) transition from single-attribute labels of highly standardized products toward multi-attribute sustainability indexing of consumer products that account for heterogeneous product categories and complex supply networks, and (2) the development of polycentric institutional arrangements to accompany ecolabeling programs that explicitly address the changing economic incentives that agents face because of the labeling program. Such arrangements must span the entire supply chain and are critical to minimize unintended consequences.

\section{Sustainable Product Indexing}

The transition from single-attribute labels of highly standardized products toward multi-attribute sustainability indexing of consumer goods should leverage single-attribute indices that are scientifically credible and verifiable. Table 1 provides an overview of this approach by contrasting the traditional single-attribute label versus our proposed multi-attribute sustainable indexing approach. If our current approach continues, (1) we will have separate labels or certifications for each impact area, (2) we will focus on prescriptive limits that ensure immediate health and safety, (3) we will measure sustainability primarily through tangible product characteristics, and (4) these efforts will be led by local and national governments seeking the best response for each issue. Such an effort may yield significant negative consequences.

Conversely, sustainable product indexing based on a social-ecological systems approach would (1) create just one or a few integrative ecolabels or programs covering all relevant impact areas, (2) focus on innovation that can bring about order-ofmagnitude improvements through a probe and learn strategy, (3) measure a product's impact across its life cycle, and (4) be led by an international coalition of government, industry, and nongovernmental organizations (NGOs), including those representing the interests of the consumer.

\section{Ecolabeling, Institutions, and Governance}

Given that ecolabeling programs simultaneously impact ecological dynamics, individual decisions, technological innovation, and business practice, management institutions must be developed that connect these different domains. This is not to suggest that an overarching, top-down agency serve as the sole conduit to connect them; local information and local action are too important in the functioning of supply chains. The past $50 \mathrm{yrs}$ of 
Table 1. Different approaches to improving product sustainability.

\begin{tabular}{ll}
\hline \hline Current single-attribute approach & Sustainable product indexing \\
\hline Different labels for every impact area & One or a few integrative labels or programs \\
Measure tangible product characteristics & Measure impact throughout product life cycle \\
Control through prescriptive limits & Improve through incentives for innovation \\
Ensure immediate health and safety & $\begin{array}{l}\text { Ensure global and long-term health and safety } \\
\text { Learn through reductionist strategies }\end{array}$ \\
Led by local and national government & $\begin{array}{l}\text { Learn through adaptation and experimentation } \\
\text { Led by global coalition of governments, industry, NGOs, } \\
\text { and local stakeholders (e.g., growers, etc.) }\end{array}$ \\
\hline
\end{tabular}

fisheries management has been a story of top-down management with a narrow focus, disregarding how management action affects economic incentives individuals face, leading to one negative unintended consequence after another (Clark 2006).

As Clark notes, early efforts focused narrowly on restricting total allowable catch. Stocks recovered, making fishing profitable even with the restricted catch, and the fleet would expand. Soon regulators faced overcapacity, induced by their own actions. As a next step, regulators tried reducing the number of boats through a buyback program. Unfortunately, the remaining boats expanded their capacity through increased horsepower, upgraded fishing gear, and larger freezers because, with fewer boats, it now made economic sense to do so. Capacity again increased, initiating a second round of buybacks, etc. In every case, management actions generated incentives for fishers to expand harvest effort. To break out of this cat-and-mouse game of the managers chasing the fishers and the fishers finding ways to circumvent new rules, effective management must begin with a focus on human behavior and the incentives generated by management action. We argue that ecolabelling programs must avoid this cat-and-mouse game altogether. Given the complexity of biological and economic systems, this is very difficult to do with the top-down management approaches used in the past.

Ecolabeling programs must take into account a dynamic and diverse landscape of incentives. To do so, we recommend a polycentric governance approach: the organization of small-, medium-, and large-scale governance units with considerable independence to make and enforce rules (Ostrom 1999). Some units are general; some are highly specialized. Polycentric governance systems can cope with the complex, dynamic biophysical systems that are the subject of ecolabeling programs because each governance unit has considerable autonomy to experiment. In experimenting with rule combinations within the smaller-scale units of a polycentric system, agents have access to local knowledge, obtain rapid feedback from their own policy changes, and can learn from the experience of other parallel units (Ostrom 1999).

\section{RECOMMENDATIONS}

The two points we make above are guiding principles that should apply to all ecolabeling efforts as we move forward into this uncharted territory. We conclude with four practical, near-term policy recommendations that can help reduce greenwashing claims and promote more quantifiable sustainableproduct indexing as the journey begins.

First, because of limited understanding of the dynamics of coupled social-ecological systems, state and national policy makers should refrain from enacting new legislation for ecolabeling and focus in the near term on enhancing scientific understanding. At best, near-term legislation will slow momentum already present in the market and, at worst, it could cause serious negative unintended consequences. Multinational retailers and final product manufacturers arguably have more influence now on product standards than any single 
government agency because of their broad reach across global supply chains. To maximize the value of this knowledge, governments should allow such businesses to develop sustainable product indexing in coalition with other groups, including government institutions, before deciding whether it is necessary to intervene. If legislators do act, they should focus broadly on the issue of sustainability and not on single issues such as carbon content, as products can be engineered for carbon neutrality while having significant unintended consequences for numerous other ecological services.

Second, an effective sustainable product index must simultaneously consider a broad spectrum of potential impacts, including climate, ecosystems, natural resources, material and energy use efficiency, and individual and community wellbeing, throughout a product's life cycle. Understanding positive synergies and negative interactions among impact areas is especially important and will contribute to determining where effort should be prioritized within the product life cycle. In the U.S., Congress should fund the National Academies or U.S. EPA to establish and lead a Scientific Advisory Council, and subcommittees on ecological and social complexity and product sustainability. This Council could (1) define product sustainability, (2) quantify current understanding of environmental, economic, and social impacts of consumer products, (3) evaluate economic opportunities for improving the sustainability of consumer products, (4) identify existing and emerging scientific programs available to quantify and communicate product sustainability, including leveraging existing certification programs and building upon the European Stepwise Environmental Product Declaration (EPD) that seeks to address small and medium business enterprise considerations (Zackrisson et al 2008), and (5) provide greater understanding of the responsibilities of the various governmental agencies that could potentially have a statutory oversight role. The appointed Advisory Council would provide recommendations to Congress on effective strategies to improve product sustainability criteria.

Third, in the U.S., the White House should address the role of pluralistic stewardship (Barrett and Grizzle 1999) by adding an Office of Sustainability to its organizational structure. This office should take the lead in coordinating federal agencies and resources for sustainability research, communication, and education. The office would help clarify agency missions in regard to sustainability and develop national policies that consider economic and security imperatives and their diverse social sustainability implications.

Finally, ecolabel systems should supplement their risk-based orientation with an innovation-based orientation. Risk-based standards create the minimal criteria that products must meet, but fail to set higher-level targets that act as incentives for leaders who wish to pursue radical innovation. The design of most products will need to be radically changed if modern societies are to attain global sustainability, and that requires forward-looking incentives that reward risk takers. Product sustainability should be considered a race to the top, not a scramble away from the bottom.

\section{CONCLUSION}

In summary, other single-attribute labels have had success in addressing discrete environmental imperatives. However, a more sustainable future requires that policies, standards, and technologies be developed that recognize the inherent complexities of the relationship between sustainable products and consumption and the socialecological systems upon which they depend. Approaches should be pluralistic, fact-based, and holistic. Ultimately, in the U.S., appropriate federal agency reorganization is needed to foster effective systems to address existing and future sustainability imperatives.

Responses to this article can be read online at:

http://www.ecologyandsociety.org/voll5/iss3/art8/responses/

\section{LITERATURE CITED}

Allenby, B., and J. Fink. 2005. Toward inherently secure and resilient societies. Science $\mathbf{3 0 9}$ (5737):1034-103.

Bacon, C. 2005. Confronting the coffee crisis: can fair trade, organic, and specialty coffees reduce small-scale farmer vulnerability in northern Nicaragua? World Development 33(3): 497-511.

Barrett, C., and R. Grizzle. 1999. A holistic 
approach to sustainability based on pluralistic stewardship. Environmental Ethics 21.

Clark, C. W. 2006. The worldwide crisis in fisheries. Cambridge University Press, Cambridge, UK.

Darnall, N., J. Jolley, and R. Handfield. 2008. Environmental management systems and green supply chain management: compliments for sustainability? Business Strategy and the Environment 18:30-45.

Deloitte and the Grocery Manufacturers Association (GMA). 2009. Finding the green in today's shoppers: sustainability trends and new shopper insights. [online] URL: http://www.deloitte. com/us/greenshopperstudy09.

Donner, S. D., and C. J. Kucharik. 2008. Cornbased ethanol production compromises goal of reducing nitrogen export by the Mississippi River. Proceedings of the National Academy of Sciences 105:4513-4518.

Folke, C., S. Carpenter, T. Elmqvist, L. Gunderson, C. S. Holling, and B. Walker. 2002. Resilience and sustainable development: building adaptive capacity in a world of transformations. Ambio 31(5):437-440.

Gereffi, G., and F. W. Mayer. 2004. The demand for global governance. Sanford School of Public Policy Working Papers, SAN04-02. Duke University, Durham, North Carolina, USA.

Greene, D. L., J. Kahn, and R. Gibson 1999. Fuel economy rebound effect for U.S. household vehicles. Energy Journal 20(3):1-31.

Hill, J., E. Nelson, D. Tilman, S. Polasky, and D. Tiffany. 2006. Environmental, economic and energetic costs and benefits of biodiesel and ethanol biofuels. Proceedings of the National Academies of Science 103: 11206-11210.

Holling, C. S., and C. K. Meffe. 1996. Command and control and the pathology of natural resource management. Conservation Biology 10(2):328337.

Horowitz, N., C. Calwell, and S. Foster. 2005. Opportunities and recommendations for reducing the energy consumption of consumer electronics products. Electronics and the Environment.
Proceedings of the 2005 IEEE International Symposium, 16-19 May 2005, Adelaide, Australia.***

Jevons, W. S. 1906. The coal question: an inquiry concerning the progress of the nation, and the probable exhaustion of our nation's coal mines. Third edition. McMillian and Company, London, UK.

Kates, R., W. Clark, R. Corell, J. Hall, C. Jaeger, I. Lowe, J. McCarthy, H. Schellnhuber, B. Bolin, N. Dickson, S. Faucheux, G. Gallopin, A. Grubler, B. Huntley, J. Jager, N. Jodha, R. Kasperson, A. Mabogunjue, P. Matson, H. Mooney, B. Moore, T. O'Riordan, and U. Svedin. 2001. Sustainability science: environment and development. Science 292(5517):641-642

Keeney, D. 2009. Ethanol USA. Environmetnal Science and Technology 43:8-11.

Mas, A. H., and T. V. Dietsch. 2004. Linking shade coffee certification to biodiversity conservation: butterflies and birds in Chiapas, Mexico. Ecological Applications 14(3):642-654.

Michener, W. K., T. J. Baerwald, P. Firth, M. A. Palmer, J. L. Rosenberger, E. A. Sandlin, and H. Zimmerman. 2001. Defining and unraveling biocomplexity. BioScience 51:1018-1023.

Ostrom, E. (1999). Coping with tragedies of the commons. Annual Review of Political Science 2:493-535.

Rappole, J., D. King, and J. Vega Rivera. 2003. Coffee and conservation. Conservation Biology 17 (1):334-336.

Sammer, K., and R. Wustenhagen. 2006. The influence of eco-labeling on consumer behavior: results of a discrete choice analysis for washing machines. Business Strategy and the Environment 15:185-199.

Scheffer, M., S. Carpenter, J. Foley, C. Folke, and B. Walker. 2001. Catastrophic shifts in ecosystems. Nature 413:591-596.

Steinzor, R. 1998. The legislation of unintended consequences. Duke Environmental Law and Policy Forum 9:95-112.[online] URL: http://www.law.du ke.edu/shell/cite.pl?9+Duke+Envtl.+L.+\&+Pol'y+F.+95 
Tenenbaum, D. J. 2008. Food vs.fuel: diversion of crops could cause more hunger. Environmental Health Perspectives 116:A254\&\#8211A257

Tillman, D. 1999. Global environmental impacts of agriculture expansion: the need for sustainable and efficient practices. Proceedings of the National Academies of Science 96:5995-6000.

The Economist. 1991. Eco-babble:environmental protection. 320(7725):84-85. 21 September 1991, London, UK.

U.S. Environmental Protection Agency (EPA). 2008. ENERGY STAR and Other Climate Protection Partnerships: 2008 Annual Report. U.S. EPA, Washington, DC, USA. [online] URL: http:// www.epa.gov/appdstar/pdf/2008AnnualReportFinal. pdf.

U.S. Environmental Protection Agency (EPA). 2009. Opportunities to reduce or avoid greenhouse gas emissions through materials and land management practices. Office of Solid Waste and Emergency Response (OSWER), U.S. EPA, Washington, DC, USA. [online] URL: http://www. epa.gov/oswer/docs/ghg land and materials mana gement.pdf.

Zackrisson, M., C. Rocha, K. Christiansen, and A. Jarnehammar. 2008. Stepwise environmental product declarations: ten SME case studies. Journal of Cleaner Production 16:1872-1886. 